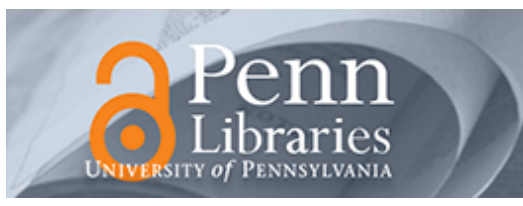

University of Pennsylvania ScholarlyCommons

Wharton Pension Research Council Working Papers

Wharton Pension Research Council

9-1-2013

\title{
Modeling Risk-based Pension Insurance Premiums
}

Martin G. Clarke

Pension Protection Fund

Follow this and additional works at: https://repository.upenn.edu/prc_papers

Part of the Economics Commons

Clarke, Martin G., "Modeling Risk-based Pension Insurance Premiums" (2013). Wharton Pension Research Council Working Papers. 120.

https://repository.upenn.edu/prc_papers/120

This paper is posted at ScholarlyCommons. https://repository.upenn.edu/prc_papers/120

For more information, please contact repository@pobox.upenn.edu. 


\title{
Modeling Risk-based Pension Insurance Premiums
}

\begin{abstract}
This paper describes how the Pension Protection Fund (PPF) in the U.K. quantifies and prices the risks it carries. It also discusses how the PPF interprets these outcomes in terms of a levy or premium to be charged to the pension plans that it protects. PPF has existed since 2005: it has experienced rapid growth as a consequence of the failure of U.K. pension scheme sponsors and the persistent underfunding of their plans, and it has withstood the global financial crisis, partly due to the Fund's ability to charge a levy consistent with the risks it faces and its skill in securing stakeholder acceptance of its process. Considering the example of the U.S. Pension Benefit Guaranty Corporation (PBGC), the PPF was able to introduce the world's first riskbased pension protection levy, a key step in winning stakeholder support for the pricing mechanism; the components of the levy-setting process are described in this paper. We examine the PPF's goal to be selfsufficient by 2030 . We also review the framework whereby investment and levy strategies can be evaluated in the context of the PPF's long-term objectives, and we describe the internal model at high level to compute measures of success of different strategies. The Board has been able to use this framework to assess the impact of a change to the basis of indexation of PPF compensation, the cost of removing its compensation cap, and the effect of a potential change in pension scheme funding valuations to permit smoothing of discount rates.
\end{abstract}

\section{Disciplines}

Economics 


\title{
Modeling Risk-based Pension Insurance Premiums
}

\author{
Martin G. Clarke
}

September 2013

\author{
PRC WP2013-14 \\ Pension Research Council Working Paper \\ Pension Research Council \\ The Wharton School, University of Pennsylvania \\ 3620 Locust Walk, 3000 SH-DH \\ Philadelphia, PA 19104-6302 \\ Tel.: 215.898.7620 Fax. 215.573.3418 \\ Email: prc@wharton.upenn.edu \\ http://www.pensionresearchcouncil.org
}

The research reported herein was pursuant to a grant from the U.S. Social Security Administration (SSA) funded as part of the Retirement Research Consortium (RRC); the author also acknowledges support from The Pension Research Council at The Wharton School. All findings and conclusions expressed are solely those of the author and do not represent the views of the SSA or any agency of the federal government, the MRRC, the PRC, or The Wharton School at the University of Pennsylvania. All findings, interpretations, and conclusions of this paper represent the views of the authors and not those of the Wharton School or the Pension Research Council. (C)2013 Pension Research Council of the Wharton School of the University of Pennsylvania. All rights reserved. 


\title{
Modeling Risk-based Pension Insurance Premiums
}

\begin{abstract}
$\underline{\text { Abstract }}$
This paper describes how the Pension Protection Fund (PPF) in the U.K. quantifies and prices the risks it carries. It also discusses how the PPF interprets these outcomes in terms of a levy or premium to be charged to the pension plans that it protects. PPF has existed since 2005: it has experienced rapid growth as a consequence of the failure of U.K. pension scheme sponsors and the persistent underfunding of their plans, and it has withstood the global financial crisis, partly due to the Fund's ability to charge a levy consistent with the risks it faces and its skill in securing stakeholder acceptance of its process. Considering the example of the U.S. Pension Benefit Guaranty Corporation (PBGC), the PPF was able to introduce the world's first risk-based pension protection levy, a key step in winning stakeholder support for the pricing mechanism; the components of the levy-setting process are described in this paper. We examine the PPF's goal to be self-sufficient by 2030. We also review the framework whereby investment and levy strategies can be evaluated in the context of the PPF's long-term objectives, and we describe the internal model at high level to compute measures of success of different strategies. The Board has been able to use this framework to assess the impact of a change to the basis of indexation of PPF compensation, the cost of removing its compensation cap, and the effect of a potential change in pension scheme funding valuations to permit smoothing of discount rates.
\end{abstract}

\author{
Martin G. Clarke \\ Executive Director of Financial Risk \\ Pension Protection Fund \\ Knollys House \\ 17 Addiscombe Road \\ Croydon, Surrey CR0 6SR \\ United Kingdom
}




\title{
Modeling Risk-based Pension Insurance Premiums
}

\author{
Martin G. Clarke
}

\section{Introduction and Summary}

This paper describes how the Pension Protection Fund (PPF) in the U.K. quantifies and prices the risks it carries. We also discuss how the PPF interprets these outcomes in terms of a levy or premium to be charged to the pension plans that it protects.

PPF has been in existence only since April 2005, but it has experienced rapid growth as a consequence of the failure of pension scheme sponsors in the U.K. and the persistent underfunding of their pension plans. The entity has so far withstood the global financial crisis, maintaining a strong financial position despite the hazardous economic climate. Part of that success lies in the Fund's ability to charge a levy consistent with the risks that the Fund faces and its skill in securing stakeholder acceptance of the process by which it does this.

In establishing the PPF, U.K. legislators considered the experience of and lessons learned from the Pension Benefit Guaranty Corporation (PBGC) in the United States. Foremost amongst those learnings was the need for greater flexibility and independent control of the levy. Indeed the PPF was able to introduce the world's first risk-based pension protection levy, a key step in winning stakeholder support for the pricing mechanism. The PPF levy is currently £630m or approximately a 5 basis point charge on scheme liabilities.

The components of the levy-setting process are described in this paper, along with the history and growth of the PPF as well as its legislative function. We also review the PPF's Funding Strategy, which is the context in which strategic decisions are made by the Board of the PPF. In establishing a clear funding objective - namely to be self-sufficient by 2030 - the Board has a publicly declared goal against which its progress can be tracked and its needs for financial resources evaluated. Without such a structure, the PPF believes there would be much less acceptance of the levy requirements within its stakeholder community. We also 
review the framework whereby investment and levy strategies can be evaluated in the context of the PPF's long term objectives, and describe the internal model at high level to compute measures of success of different strategies. In a separate exercise the Board has set its risk appetites and agreed a minimum level of long term security against its funding target in much the same way that a financial company (bank or insurer) would do to optimize its capital usage. The sensitivity analysis of the results that the PPF derives each year helps the Board assess changes to its levy needs. As well as shifts in the risk landscape, the Board has been able to use this framework to assess the impact of a change to the basis of indexation of PPF compensation (from Retail Prices Index to Consumer Prices Index), the cost of removing its compensation cap and the effect of a potential change in pension scheme funding valuations to permit smoothing of discount rates.

The PPF's internal model is a stochastic tool that encompasses the main financial and economic risks faced by the Fund. It incorporates many behavioral assumptions such as the rate of closure of defined benefit plans and the shift over time to less risky investment strategies. The model produces distributions of outcomes and allows the Board to understand both the expected outturn and the range of possibilities. Such output is used by the Board to inform its periodic decisions about the size of the PPF levy, using risk-based and schemebased elements.

We conclude our discussion with a review of four lessons from the U.K. experience that may be applicable to the PBGC in the United States.

\section{The Pension Protection Fund}

The PPF was created in response to concerns about the fate of members of underfunded defined benefit (DB) pension schemes should the scheme sponsor become insolvent. In 2002 and 2003, publicity around cases such as Allied Steel and Wire highlighted 
the growing number of instances in which employees in these circumstances were left with very much lower levels of pension than expected. This contributed to what many described as a "pension crisis" undermining public confidence in final salary pension schemes in the U.K.

The idea of a Central Discontinuance Fund had been considered by the Pension Law Review Committee a decade previously but it was not considered appropriate to pursue the idea at that time. But in 2003 the Government decided to act, announcing its plans in a Pensions White Paper to create the PPF in order to provide compensation for members of private sector, defined benefit pension schemes which wound up on the employers' insolvency with insufficient assets to meet their liabilities. The 2003 White Paper culminated in the Pensions Act 2004, and in April 2005 the PPF was formed.

Figure 1 here

Established as a Statutory Corporation, the PPF is run by a Board that is independent of the U.K. Government. Powers conferred on the Board give it responsibility inter alia for managing the calculation and application of the Pension Protection Levy and setting the Fund's investment strategy. A primary driver for conferring these powers on the Board was to ensure that the activities of the PPF would be independent of, and not have to be underwritten by, the Government and ultimately taxpayers.

Broadly speaking, the PPF provides two levels of compensation to pension plan participants. For individuals that have reached their scheme's normal pension age or, irrespective of age, are either already in receipt of survivor's pension or a pension on the grounds of ill health, the PPF will generally pay 100 percent of the pension in payment immediately before the insolvency event. For the majority of people under their scheme's normal pension age, the PPF will generally pay 90 percent of the pension the individual had accrued (including revaluation) immediately before the insolvency event. The individual's compensation is revalued in line with the increase in inflation as measured by the Consumer 
Prices Index (CPI) between the assessment date and the commencement of compensation payments. This revaluation is subject to a cap of 5 percent compound per annum in respect of compensation attributable to pensionable service prior to 6 April 2009, and a cap of 2.5 percent compound per annum in respect of compensation attributable to pensionable service on or after 6 April 2009.

Compensation for plan participants is subject to an overall annual cap. In April 2012, this cap was £30,644.85 at age 65 after application of the 90 percent factor, with the cap being adjusted according to the age at which compensation comes into payment. Once compensation is in payment (for either category of member), the part that derives from pensionable service on or after 6 April 1997 is indexed each year in line with CPI inflation capped at 2.5 percent.

While the PPF has the ability to alter the Pension Protection Levy (subject to certain statutory limits) to meet its liabilities, in extreme circumstances it can also reduce compensation. First, revaluation and indexation can be reduced by the PPF. Second, levels of compensation can be reduced by the Secretary of State on the recommendation of the Board of the PPF. To date, the PPF has not articulated the circumstances in which these powers might be exercised and for the purpose of its financial management such scenarios are not explicitly modeled.

In order to fulfill its broader statutory objectives, the PPF must have sufficient funds to pay compensation to the members it protects. The agency's revenue currently derives from four sources: the assets of pension schemes that transfer into the Fund, recoveries from the insolvent sponsoring employers of those schemes, the annual Pension Protection Levy, and returns on invested assets. Table 1 shows the development of the PPF balance sheet in the eight years 2005/2006 to 2012/2013.

Table 1 here 
In the above table, the funding ratio is based on the assets and liabilities of the Fund, measured according to PPF valuation assumptions. These data include those of schemes in assessment that are anticipated to transfer to the Fund. Claims are measured in terms of the deficits of schemes entering an assessment period in the relevant year, in accordance with the actuarial basis set under the terms of Section 179 of the Pensions Act 2004.

Although short term prospects for the PPF may be challenging owing to the current global economic climate, the long term decline in private sector DB provision and the influence of regulation towards improved funding levels both tend to suggest that the risk to the PPF balance sheet is likely to diminish over time. A number of factors are likely to contribute to this, including regulatory intervention, a move to liability-driven investment, and the overall decline in the number of schemes as they transfer their liabilities to the insurance regime, enter the PPF, or otherwise become ineligible for PPF protection.

Against this background, the PPF recognizes that there will come a point in time when the Fund is unable to rely on surviving schemes to amortize any deficit it may have accrued. The PPF's current objective therefore is to become self-sufficient by 2030 .

\section{Funding strategy}

The PPF's financial operating model. Most financial firms have clear objectives around which they build their business strategies and track performance. In the case of the PPF, its stated vision is “To protect peoples' futures" and its mission is "To pay the right people the right amount at the right time.” A number of financial objectives might be congruent with these statements. The PPF Board's objective is to fulfill its vision and mission, taking into account the totality of the PPF financial model, namely its assets and liabilities from both past and future claims, and its levy income. 
The PPF's financial operating model is illustrated in Figure 2 This shows the flows of money into the Fund and the outputs from the investment processes, being the compensation payable to former members of pension schemes that have transferred into the PPF.

Figure 2 here

The PPF financial objective is self-sufficiency. It is inevitable that the PPF will continue to experience failure of scheme sponsors and consequently future claims. A claim is quantified by the PPF as the size of the scheme's deficit as of the date of insolvency, measured according to the PPF's published Section 179 valuation guidance and assumptions. In particular, it should be noted that the Section 179 deficit is assessed by reference to PPF compensation levels rather than the full benefits under the scheme's rules. It is however likely that the impact of claims on the Fund will decline over time, because:

- The long term expectation is that pension scheme funding will improve on account of the efforts of trustees, sponsors, and the Pensions Regulator;

- Schemes are expected to participate increasingly in risk mitigation strategies such as funding triggers, and interest rate and longevity hedging;

- Current activity points to growth in pension buy-out and buy-in activity that reduces risk to the Fund. It is expected that the market capacity for liability de-risking will increase over the coming years from its present level; and

- The trend towards closure of schemes to new entrants and new accrual is expected to continue, as is the increasing preference for defined contribution schemes as the solution to employer-sponsored pension provision.

There are, of course, scenarios where these expectations might not be met and which must be included in any financial analysis of the PPF. Nevertheless, over a long period, the expected decline in the scale of claims on the Fund is likely to lead to a point when the off- 
balance-sheet risks (namely the risks associated with future claims on the Fund) are much less significant than the on-balance sheet risks.

Any funding shortfall experienced by the PPF at that time would become a significant burden on the remaining levy payers. Furthermore, as the level of risk in the eligible defined benefit universe shrinks over time, it would be desirable for the Pension Protection Levy to reduce in proportion. Indeed, the PPF New Levy Framework introduced from 2012/2013 onwards has a "bottom up" principle, in which the levy payable by an individual scheme is closely related to that scheme's own risk characteristics. It would be unsatisfactory if, several years hence, a large levy needed to be raised to deal with a substantial PPF shortfall at a time when the base of levy-paying schemes had shrunk considerably and almost all of them were well funded.

The PPF therefore believes that there needs to be a Funding Horizon by which time the PPF should be "self-sufficient".

What is meant by self-sufficiency? The use of the term "self-sufficiency" is becoming increasingly common in pensions work. It is important, however, that the term is carefully defined to avoid misunderstanding. In the context of its Financial Objective, the PPF has defined "self-sufficiency" to mean having sufficient assets to cover liabilities without the need to take future risk for which future levies would be required, specifically:

- Being fully funded on a reasonably risk-free measure of liabilities;

- Having removed exposure to interest rate and inflation risk as far as possible;

- Having removed exposure to financial market risk as far as possible; and

- Having acquired protection against residual risks such as longevity and residual insolvency risk.

Self-sufficiency therefore implies that the PPF would no longer need to raise levies in order to maintain its funding position. The use of the phrase "reasonably risk free” recognizes 
that there are no truly risk free assets, so it means that the Fund at that point in time would not need to take additional investment risk. In practice, this means a mark to market valuation of the liabilities, by reference to a notional portfolio of assets consisting of cash plus appropriate zero-coupon interest rate swaps contracts and inflation swaps contracts plus gilt strips (or notional gilt strips). In order to achieve this target, it is the PPF's intention to remove risk gradually over a period of time, using market instruments where available and cost-effective.

The alternative to this strategy is to allow risk to the PPF balance sheet to persist in the long term. This may lead to a potentially lower levy in the run-up to the end of the Funding Horizon but with increased probability of a sizeable deficit thereafter. This, in turn, could necessitate substantial levies on schemes still extant beyond the Funding Horizon, should investment, longevity, or credit conditions prove adverse.

The funding horizon. The PPF has considered how it should quantify the expected decline in the risk of insolvency and at what point to draw the line in terms of setting a funding target. The deliberations of the PPF Board in 2010 concluded that 20 years was an appropriate timescale to aim for (i.e. the year 2030), although it accepted that there was an element of subjectivity in this choice.

The length of the Funding Horizon is important in ensuring the Pension Protection Levy follows a balanced and stable trajectory over time. A short horizon may lead to the PPF charging excessive levy over the short term, as it aims for the Fund to become self-sufficient in the face of persistent financial risk. On the other hand, an extended horizon would increase the likelihood of the Fund falling short of self-sufficiency at a point where there remains little potential for continued levy.

It is important to note that self-sufficiency is only a target for the year 2030. During the funding period, the PPF must accept the risk of further claims, and it has determined that 
it will assume a certain amount of investment risk during this period. This strategy serves to mitigate the impact on the Pension Protection Levy, through the expectation of investment returns in excess of the "risk-free" rate.

The PPF Board chose the 20-year horizon after considering the following factors:

- The maturing profile of its liabilities;

- The expected decline in its exposure to the effects of sponsor insolvencies; and

- The decreasing size of the eligible universe of levy payers.

In broad terms, the Board considered that the risk to the PPF, both within and outside the Fund, was likely to be much diminished by 2030, and this was the primary reason for the choice of 2030 as the Funding Horizon.

Owing to the closure of many schemes to new entrants and accruals, and especially those schemes most likely to be candidates for PPF entry in future, the duration of PPF liabilities is expected to shorten over the same timescale. This gave further support to a strategy that aims to focus solely on matching the liabilities rather than taking investment risk after a point in time. Figure 3 below shows the maturing profile of PPF liabilities. ${ }^{1}$ It is projected that by 2030:

- The average age of DB scheme members will have increased from 56 to 71 (pensioner average age rising from 68 to 76, non-pensioner average age moving from 47 to 59); and

- Around 70 percent of scheme members will be pensioners, up from around 40 percent today.

As a result, the duration of the Fund's liabilities is expected to reduce from 21 years to 12 years. This facilitates the matching of compensation payments using conventional investment

\footnotetext{
${ }^{1}$ The spike at around age 65 is also reflected in population statistics and is partly explained by the post-war baby boom.
} 
techniques, as a smaller proportion of liabilities is projected to fall outside the term of longdated gilts.

Figure 3 here

Claims and scheme membership projections therefore point to a much improved risk environment for the PPF balance sheet in 2030. If the Fund arrives at this date in a sound funding position, with assets that match its liabilities as far as possible and with arrangements in place to protect it from residual risks, there should only be a low risk of the Fund failing to meet its financial obligations. A 20-year period from 2010 has therefore been set as the horizon over which the Board will seek to achieve a resilient balance sheet.

While the PPF has stated an intention to target self-sufficiency over a 20-year horizon, this timeframe is not considered by the Board to be immutable. A shorter time horizon than 2030 would be appropriate if risks to the PPF were much reduced at an earlier juncture. On the other hand, stressed economic conditions and persistent risk could imply an extension of the Funding Horizon beyond 2030.

Protecting against residual longevity and unexpected claims risk. Risk to the PPF balance sheet will not be entirely eliminated by 2030. The Fund aims to remove market, interest rate, and inflation risk using appropriate investment techniques. Nevertheless, the risk of unexpectedly high claims and member longevity is likely to persist. The Fund will also need to deal with operational hazards, such as the risk of counterparty insolvency and the risk of an expense overrun. The materiality of counterparty risk undoubtedly requires further analysis and monitoring. The possibility of an expense overrun also requires monitoring and will become more material when the Fund reaches maturity.

It may be possible to protect against a proportion of residual longevity and unexpected claims risk. Instruments to hedge longevity, for instance, are already available. But the markets providing insurance against these residual risks remain at a relatively early 
stage of development, compared to the pool of potentially insurable liabilities. The Fund's liabilities are expected to grow substantially to 2030. It is currently unclear whether such markets will be sufficiently large and sophisticated to absorb the full extent of PPF claims and longevity risk. The PPF therefore considers it prudent to target a Funding Margin above best-estimate liabilities in order to protect against these residual risks. At the same time, it recognizes that it must balance the interests of different generations of levy payers and members in determining the size of this margin.

In order to identify a suitable margin, the Board considered stochastic modeling of longevity and claims using the PPF's own internal model (the Long-Term Risk Model, described below). The first step was to produce an expected PPF and scheme profile at 2030 using model output, credit transition matrices, and current mortality tables. A range of scenarios was then generated for insolvencies over five years and longevity over the outstanding lifetime of the Fund. This was applied to the expected PPF and scheme profile at 2030, providing a set of outcomes for claims and PPF funding. From these outcomes, it was possible to examine the protection against combined longevity and claims risk provided by various sizes of reserve. The estimated relationship between the size of margin and the extent of protection is illustrated below in Figure 4.

Figure 4 here

The PPF is targeting a Funding Margin equivalent to 10 percent of liabilities to protect, with 90 percent confidence, against unexpected claims over five years and longevity over the outstanding lifetime of the Fund. This target will not be static over time, however; it will be re-evaluated against changing economic and demographic circumstances. A useful comparator for the 10 percent margin is the embryonic IORP solvency initiative in Europe which, though unlikely to be realized for many years, proposes an eight percent solvency capital margin above the value of the liabilities for pension funds. 


\section{Funding framework}

The risk return trade-off for the PPF. The number, size, and shortfall in respect of those schemes that enter the PPF are beyond the PPF's control, but the investment strategy and the size of the levy that the PPF seeks to raise are clearly within its control. The PPF's Funding Framework is a useful tool with which a range of decisions, including those related to levy and investment strategies, can be evaluated. Such a framework also represents a rational basis for communicating with key stakeholders.

Development of the PPF Funding Framework has leaned heavily on the language and principles applied to both pension funds and insurance undertakings. For example, Urwin et al. (2001) refer to the financial mission of a pension fund including key financial goals; secondary financial goals and the risk measure. And in the insurance context, Shaw et al. (2010) note the main components of economic capital to be risk measure; probability threshold and time horizon, the most well-known examples of which are the one-year 99.5\% Value at Risk (VaR) found in insurance.

The PPF's probability threshold is in effect a guideline probability of reaching the Financial Objective over the Funding Horizon. This was established in 2010 when the PPF Board expressed comfort with a probability of reaching the Financial Objective over 20 years of 80 percent, known as the "probability of success." In reaching this position, which was also subject to informal stakeholder consultation and subsequent exposure through the publication of the Funding Strategy, the Board had to accept that success cannot be guaranteed under a principle that the possibility of any adjustment to compensation levels or indexation would not be formally incorporated into its financial planning. 
In order to be able to express its appetite for financial risk and to provide a quantification that will facilitate analysis of risk return trade-offs, the PPF has selected two risk measures:

- A downside risk measure (sometimes referred to as drawdown) being the maximum deficit reached by the Fund under the $90^{\text {th }}$ percentile adverse scenario. It is a comprehensive measure that combines both the insurance risks of future claims on the Fund and the asset and liability risks of the Fund's annuity book. The measure reflects the near worst case scenario where the Fund may inherit potentially irrecoverable deficits and is used to inform the Board on strategic levy and investment decisions; and

- The second risk measure is the volatility of the funding level assuming no further claims on the Fund. This measure reflects short term uncertainty in the PPF's own funding level and is used to express the Board's appetite for investment and funding risk and to inform more detailed day to day investment decisions.

The sensitivity of the downside risk and probability of success measures to controllable factors such as investment strategy and levy collections, and to key assumptions such as current scheme and the PPF funding levels, is shown in Table 2.

Table 2 here

As noted above, the practical risk return trade-offs available to the PPF center on the investment and levy strategies of the Fund. Under a new policy introduced for the 2012/2013 year, levy parameters are now set triennially following an analysis of the Funding Framework. In addition to the quantitative outputs such as those from the internal model within the Funding Framework, the Board will also consider qualitative issues such as the balance between protection and affordability of the PPF levy. 


\section{PPF's Internal Model}

The PPF's Long-Term Risk Model. Internal models are more commonly associated with risk capital assessments within insurance entities. Although the PPF is not a capitalized entity like an insurance company, an internal model can nevertheless help to assess the full extent and range of risk that the PPF faces. Such assessments are vital to a number of core PPF decisions, most notably those on the total Pension Protection Levy and on the design of an appropriate investment strategy.

The PPF has developed a model capable of capturing, quantifying and expressing the potential impact of all primary risks to the PPF balance sheet: the so-called Long-Term Risk Model (LTRM). The LTRM is a stochastic claims and balance sheet model that generates an extensive range of asset return, insolvency and longevity scenarios over a chosen time horizon, and on this basis projects a distribution of possible PPF balance sheet outcomes.

The projection process begins with the generation of 1,000 economic scenarios. Each economic scenario is a set of projected paths for relevant asset prices (including bond yields, equity prices and risk-free rates). These are obtained from a third party supplied Economic Scenario Generator (ESG). The largest PPF-eligible pension schemes are modeled individually, with the remaining schemes pooled into groups according to demographic and risk similarities.

To capture insolvency risk, the PPF models pension scheme sponsors transitioning each year between eight different credit ratings, ranging from AA to D (where D constitutes a default). The probability of transitioning to a given credit rating depends on the sponsor's current rating, its industry sector, the current state of the economy, and the company's own idiosyncratic risk. This latter element reflects the fact that companies face their own unique risks that are uncorrelated with their industry and the wider economy. The PPF uses 500 different scenarios of idiosyncratic risk. Each of the 500 risk scenarios is mapped to each of 
the 1,000 economic scenarios (providing 500,000 scenarios in all); with the insolvency dynamics adjusted to reflect the degree of stress at play in the economy. Funding paths therefore combine with insolvency dynamics to determine the profile and size of claims on the Fund (see Figure 5).

Figure 5 here.

PPF assets and liabilities are rolled forward under each scenario, taking account of investment returns and movements in the discount rate. It is assumed that the PPF balance sheet is unaffected by changes to interest and inflation rates owing to the Fund's policy of hedging out these risks. The funding of schemes in the PPF-eligible universe is rolled forward in a similar manner. These deficits are transferred onto the PPF balance sheet at the point at which they occur. Levy collections are also modeled explicitly, taking into account the main features of the PPF's New Levy Framework, for example the way that funding risk varies under different economic scenarios. The result is a distribution of PPF balance sheet outcomes over a chosen horizon that takes account of all primary funding risks. Figure 6 shows the distribution of balance sheet outcomes from the Fund's 31 March 2012 base case.

Figure 6 here

The value of liabilities at any particular time step is expressed in terms consistent with the contemporaneous market parameters (such as interest rates and inflation assumptions) which underlie the market value of the assets. The PPF uses a stochastic mortality model that allows for rates of mortality improvement to vary in different scenarios. The table currently used is generated by the Cairns-Blake-Dowd (2007) mortality model with the cohort and curvature effects.

Modeling assumptions and limitations. In projecting forward the PPF balance sheet, the LTRM models the behavior of asset returns and scheme sponsor insolvencies. Modeling techniques are insufficient, however, to capture many of the additional dynamics affecting 
pension scheme risk, especially those relating to "scheme behavior". In these cases, subjective assumptions are used, a selection of which includes the following:

- Scheme contributions are determined in accordance with current recovery plans, as reported to the Pensions Regulator;

- Schemes reduce the risk of their investments over time (migrating on average to 85 percent allocation to long-dated bonds); and

- No new schemes become eligible for PPF protection.

Where assumptions such as the above are material to the risk assessments or decisions being made, it is important that their choice is appropriately governed and that the effect of these choices is explored. In the case of the PPF, key model assumptions are set at the Board level and their impact assessed through the use of sensitivities.

The internal model is not subject to uniformly-applied assumptions regarding the risk premia for investment in equity or other return-seeking asset classes. Instead, as noted above, asset returns are generated stochastically by the ESG. Observed data and current market information inform long-term averages around which stochastic projections fluctuate. In the projections carried out at an effective date of 31 March 2012, the risk-free investment return, in this case the short-term return on cash stabilizes at a long-term average of around 5 percent per annum, with an average risk premium for equity investment of around 3.5 percent per annum. Sponsor insolvency probabilities are assumed to exhibit a degree of correlation with equity market conditions.

For the modeling of interest rates, there is an implicit assumption of mean reversion which could disguise the exposure to extreme and historically unprecedented market scenarios. Since these seemingly unlikely scenarios may represent significant financial risks to the Fund, their effect should be explored through further analysis. Stress testing of the key risk metrics is carried out using assumptions devised from economic analysis of potential 
future scenarios of the world economy. These stress tests are used to study the resilience of the Fund to various shocks, identify exposures and assist with the planning of mitigations.

As with any financial or economic model, it is important to exercise appropriate caution when analyzing LTRM output. Economic models are not infallible; there is no guarantee that future outcomes will conform to dynamics observed in present and past data. In order to minimize the risk of misleading output, care must be taken to review and update the model on a regular basis and to reconcile its results to previous output and known outcomes.

\section{Pricing and Sharing the Risk}

Overview of the PPF charging mechanism. The Pension Protection Levy is determined in two steps. First, the Board determines the aggregate amount of levy funding that it wishes to collect. This amount is then divided up between schemes according to their risk for the estimated Risk-Based Levy (RBL) component, and according to their size for the estimated Scheme-Based Levy (SBL) component. Prior to the 2012/2013 levy year this was an annual exercise This approach was, to a large extent, a "top-down" charging mechanism in that an individual scheme levy was a function of the total to be collected and that scheme's risk characteristics relative to the general population.

The PPF Board moved to a triennial cycle from 2012/2013 onwards. Under the new arrangement, the levy parameters are fixed for the three years so that levy payers have greater predictability of costs during that period (though the system has less predictability of levy income). During each three-year period, therefore, the levy will be "bottom-up" whereby an individual scheme's levy depends solely on that scheme's individual risk factors and the aggregate levy will be the sum of the individual levies. This new framework has several features: 
- Parameters of the levy formula are fixed for at least three years so that individual levies move in line with individual scheme risk;

- The impact of market volatility is reduced by a smoothing mechanism and there is an allowance for individual schemes' investment risk in the calculation of the underfunding level;

- Emphasis is shifted away from insolvency risk towards underfunding risk, with a compression in the scale of insolvency probabilities and the number of levy bands reduced from 100 to 10 ; and

- The levy rates themselves include a margin to accord more closely to market pricing levels, with the result that the range in rates between strong and weak sponsors is much narrower.

Setting the levy estimate. In setting its levy requirements, the PPF Board is mindful of remaining on track to achieve its funding objective by the end of its chosen Funding Horizon in 2030. The Board has expressed a level of comfort for the probability of achieving this objective set at $80 \%$ in 2010 , but which is expected to gradually increase and converge to $100 \%$ by 2030 . The levy decision is informed by analysis from the internal model described previously, together with appropriate sensitivity and scenario analyses. In particular, one of the outputs of the model is the probability of achieving the PPF's Funding Objective. In addition to the quantitative information and mindful of the limitations of models, the Board exercises considerable judgment and takes into account a wide range of qualitative factors in making a levy decision.

The Pension Protection Levy cannot, under the Act, exceed a Levy Ceiling initially fixed by the Secretary of State for Work and Pensions; it is now indexed annually in line with National Average Earnings. For the 2012/2013 levy year the ceiling was £934m. The Pensions Act also specifies a 25\% cap on any year-on-year increase in the levy estimate. 
Indeed following the first year of the new levy arrangement, in which the level of risk through underfunding rose dramatically as long bond yields hit historic lows, the Board had to intervene to restrain the increase in the levy estimate to ensure continued affordability.

Sharing the PPF levy among schemes. The PPF Levy comprises a "Risk-Based Levy" (RBL), based on individual scheme risk factors, and a "Scheme-Based Levy" (SBL) which depends only on the size of the scheme and is set in proportion to scheme liabilities on a Section 179 basis. The estimated SBL must not represent more than $20 \%$ of the estimated total levy collection. In effect the SBL is a cross-subsidy of the levy of small schemes by larger ones, and the PPF has stated that it will be set at a level to cover only the cost of any capping of the RBL that may be made on grounds of affordability.

The Pensions Act requires the Board to take at least two risk factors into account in the calculation of the RBL, namely underfunding and insolvency risk. The Board may also take investment risk into account and, from 2012/2013, it has begun to do so by basing its formula on values of assets and liabilities that are stressed according to an adverse investment scenario.

Figure 7 here

\section{Conclusions}

Here we provide an explanation of the PPF levy-setting process, explain the framework around which the levy decisions are made, and outline the success measures designed to show the robustness of the Fund on a prospective basis. Some of the methodology was derived from the insurance sector, but the PPF approach differs from a typical insurance pricing approach because of its unique structure.

A proprietary insurance company would calculate the premium as the expected cost of claims plus the cost of servicing the capital that is held against the risk and which represents 
the level of security that is being adopted by the company. PPF, of course, is not a proprietary model; its resources are the future levies that are raised - a sort of contingent capital - and it has no real basis for establishing a unit cost of capital. However the process of setting the aggregate levy requirements using stochastic methods that evaluate the risks and direct a level of pricing consistent with the Board's risk tolerance or risk appetite is very similar to a proprietary model, albeit in conceptual terms.

The parallels continue into the division of levy between the 6,300 eligible schemes where the levy rates, which formerly were based on one year probabilities of default and are now closer to market rates that implicitly incorporate a cost of capital. These levies thus reflect the contribution to risk of individual schemes. Nevertheless it must be remembered that this stage of the process is essentially a levy-sharing exercise, not an individual riskpricing exercise. PPF does, however, monitor its levy amounts against the premium that would be charged by a commercial insurer with capital costs to bear.

The paper has also shed a light on the complexities of the risk landscape that must be factored into the levy pricing mechanism. PPF's claims experience has typically been a steady flow of new claims, but the amounts vary markedly. Deficits inherited range from those counted in single millions of pounds right up to over half a billion pounds. PPF has yet to experience a sustained increase in claim frequency, although one is often predicted in connection with the economic recovery. The PPF is still vulnerable to an extremely large claim, albeit an unlikely one. Capturing these risks in a single model is challenging, and then the risk is also affected over the long term by the behaviors of scheme Trustees and indeed the changing landscape of regulation. Both factors must be considered either in a base case or in a sensitivity analysis. 


\section{Postscripts: Lessons from the U.K. experience}

If I were to address what the U.S. pension protection regime might learn from its younger and much smaller counterpart in the United Kingdom, I would identify four areas to consider (with much humility):

A levy that is consistent with the cost of risk. The ability to set a levy that is linked to the financial requirements of the Fund and is shared out among insured plans according to individual plan risk has helped maintain the PPF resilience throughout the global financial crisis.

In aggregate, the claims on the PPF, as measured by the Section 179 deficits of schemes entering the Fund, has represented $97 \%$ of the aggregate levy collected during PPF's eight years of existence. The Fund has gained a measure of stakeholder acceptance for the levy through a clear financial objective and by linking the individual scheme levy to the risk posed to the PPF by that scheme. This is in contrast to the U.S. regime, in which the levy is based on scheme memberships and has not been sensitive to the level of risk in the system.

So far, the U.K. has been able to build a margin into its levies and has avoided a legacy issue of large inherited deficits becoming too great, or even irrecoverable. Were such a situation be allowed to develop, it would become harder to gain stakeholder acceptance to pay for both the prospective and the inherited risks. In the U.S., it seems that this position has been reached and that any move towards a risk-led approach to levies may have to be accompanied by measures to deal with the legacy issues.

Clearly expressed financial objectives. As noted above, the PPF has set a very clear financial objective, namely, to be self-sufficient by 2030. This has provided a firm quantitative framework to evaluate levy and investment strategies, as well as providing a mechanism for informed stakeholder engagement with the Fund's financial resilience. By contrast, the PBGC's financial objectives are not as clear and its investment strategies have 
oscillated at times, between the conflicting priorities of hedging downside liability risks and aggressive growth strategies. The PIMS model focuses on a 10 year time horizon and analyzes the funding level at that time, without having the firm context of knowing what the target is. In many ways this is understandable, but it is not conducive to good planning or stakeholder dialogue.

Given the almost overwhelming legacy issues faced by the PBGC today, it might seem that any strategy is destined to fail unless substantial external funding is acquired. In my opinion, this should not deter the PBGC from constructing a financial objective that accepts reality while attempting to make realistic improvements using levies and investment strategies. I am drawn to the concept of an objective that seeks to guarantee the pensions payable over a period of $\mathrm{x}$ years and to increase that period incrementally in each future year. Such a framework would accept the reality that the PBGC cannot guarantee all its current commitments without some future injection of funds. It would also encourage the protection of downside liability risks in order to make the guaranteed payments and allow some flexibility to take investment risks in the expectation that these will be rewarded and allow the funding position (and the guarantee period) to improve. This would further enable the modeling work of PIMS to become more relevant and enable better dialogue on the real issues facing the PBGC.

Ownership and governance of investment risks. The clarity that PPF has achieved through its governance arrangements means that ownership of, and appetite for, risks in general and investment risk in particular is well understood and highly transparent. In particular, the PPF Board has set a budget for investment risk that is delegated through its investment committee to the executive and its external fund managers. The Fund has established a notional portfolio of low risk investments that replicate its liabilities and that is consistent with its valuation assumptions. This replicating portfolio forms the investment benchmark 
from which performance and risk are measured. The investment committee devises a multiasset investment strategy to optimize long term performance against the benchmark whilst remaining within the Board's risk tolerance. Generally this strategy will hedge away unrewarded risk and allocate money to a diversifying range of asset classes with their own benchmarks that collectively seek to outperform the replicating portfolio by a target of $1.8 \%$ per annum. The accountability for the collective performance of these strategic benchmarks lies with the investment committee. The execution strategies within each asset class and the risk and performance of the assets in relation to asset class-specific benchmarks are the responsibility of the in-house investment team and the external managers they select.

Such a structured approach paired with clear statements of risk appetite are not evident within the governance arrangements of PBGC. Investment performance is measured against a soft benchmark of a blend of equity and bond investments, but this benchmark is simply a comparator. It does not appear to feature in the roles and responsibilities of the various links in the investment chain, crucially, it bears no relation to the liabilities of PBGC.

One consequence of this is that the ownership and governance of the mismatching risks between assets and liabilities are not immediately clear. Yet the management of performance and risk within the whole investment area is likely to be compromised by insufficiently clear objectives.

Model assumptions and limitations. The PPF has a comprehensive internal model that is used for risk analysis and strategy evaluation, but as with all such models, it has limitations and the users of such models should be aware of these limitations. In the case of the PPF, the Board owns the model assumptions and is therefore encouraged at a high level to be familiar with the key assumptions and their materiality. Members of the Board also undertake training on financial models and how they can engage with and challenge model outputs, for example 
by applying tests of reasonableness. The main assumptions in the PPF model are also published each year within the PPF's annual review of its funding strategy.

Good actuarial practice encourages the providers of actuarial information and model outputs to understand the purposes for which the information will be used. Where decisions are to be made or opinions formed from that information, then those assumptions material to the decision should be clearly stated and, where appropriate, sensitivities used to illustrate the effect of differences in the material assumptions.

Models such as that used by the PPF or the PIMS model used by PBGC can become victims of their own inherent complexity. Of necessity, there are many components such as the economic and market factors that influence investment performance and also insolvency rates, assumptions about behaviors such as scheme closures, buy outs, or pensions commutation, and regulatory effects. This makes it difficult to properly inform the users of the model about the limitations and sensitivities to changes in material assumptions.

A model's utility as a practical tool is formed by the clarity of the purpose for which it is being used, the governance around its assumptions, and a clear understanding of its limitations and a quantification of its sensitivity to changes in key assumptions. A great deal of effort can go into the design, build, and the assumption-setting, and in many respects this is a continuous process of iteration. But unless there is clarity of purpose and a good sense of materiality, this effort can simply become a misplaced search for elusive perfection. 


\section{References}

Cairns, A. J. G., D. Blake, K. Dowd, G. D. Coughlan, D. Epstein, A. Ong, and I. Balevich (2007). “A Quantitative Comparison of Stochastic Mortality Models using Data from England and Wales and the United States,” North American Actuarial Journal, 13(1): $1-35$.

Pension Protection Fund (PPF) (2006). Annual Report \& Accounts 2005/06. London, UK: The Stationery Office.

Pension Protection Fund (PPF) (2007). Annual Report \& Accounts 2006/07. London, UK: The Stationery Office.

Pension Protection Fund (PPF) (2008). Annual Report \& Accounts 2007/08. London, UK: The Stationery Office.

Pension Protection Fund (PPF) (2009). Annual Report \& Accounts 2008/09. London, UK: The Stationery Office.

Pension Protection Fund (PPF) (2010). Annual Report \& Accounts 2009/10. London, UK: The Stationery Office.

Pension Protection Fund (PPF) (2011). Annual Report \& Accounts 2010/11. London, UK: The Stationery Office.

Pension Protection Fund (PPF) (2012). Annual Report \& Accounts 2011/12. London, UK: The Stationery Office.

Pension Protection Fund (PPF) (2013). Annual Report \& Accounts 2012/13. London, UK: The Stationery Office. Forthcoming.

Pension Protection Fund (PPF) and The Pensions Regulator (2006). The Purple Book: DB Pensions Universe Risk Profile. London, UK: PPF. 
Pension Protection Fund (PPF) and The Pensions Regulator (2007). The Purple Book: DB Pensions Universe Risk Profile, 2007. London, UK: PPF.

Pension Protection Fund (PPF) and The Pensions Regulator (2008). The Purple Book: DB Pensions Universe Risk Profile, 2008. London, UK: PPF.

Pension Protection Fund (PPF) and The Pensions Regulator (2009). The Purple Book: DB Pensions Universe Risk Profile, 2009. London, UK: PPF.

Pension Protection Fund (PPF) and The Pensions Regulator (2010). The Purple Book: DB Pensions Universe Risk Profile, 2010. London, UK: PPF.

Pension Protection Fund (PPF) and The Pensions Regulator (2011). The Purple Book: DB Pensions Universe Risk Profile, 2011. London, UK: PPF.

Pension Protection Fund (PPF) and The Pensions Regulator (2012). The Purple Book: DB Pensions Universe Risk Profile, 2012. London, UK: PPF.

Pension Protection Fund (PPF) and The Pensions Regulator (2013). The Purple Book: DB Pensions Universe Risk Profile, 2013. London, UK: PPF. Forthcoming.

Shaw, R. A., A. D. Smith, and G. S. Spivak (2010). "Measurement and Modelling of Dependencies in Economic Capital,” British Actuarial Journal, 16(3): 701-721.

Urwin, R. C., S. J. Breban, T. M. Hodgson, and A. Hunt (2001). "Risk Budgeting in Pension Investment,” British Actuarial Journal, 7(3): 319-364. 
- The PPF universe of eligible DB schemes comprises 6,300 pension schemes with 12 million members and aggregate liabilities of $£ 1 \mathrm{tn}$, measured under the basis set in accordance with Section 179 of the Pensions Act 2004.

- 550 pension schemes with, in total, over 150,000 members have transferred to the PPF. An additional 250 schemes with 150,000 members are in a PPF assessment period during which the scheme is assessed for PPF entry.

- The PPF's balance sheet has grown significantly to the point where, as at 31 March 2013, an estimated $£ 13$ billion of assets are under direct PPF management, with a further $£ 6$ billion of assets managed by schemes that are in an assessment period.

Figure 1. Key facts about the PPF (as at end March 2013). Source: PPF (2006-2013); PPF and The Pensions Regulator (2006-2013).
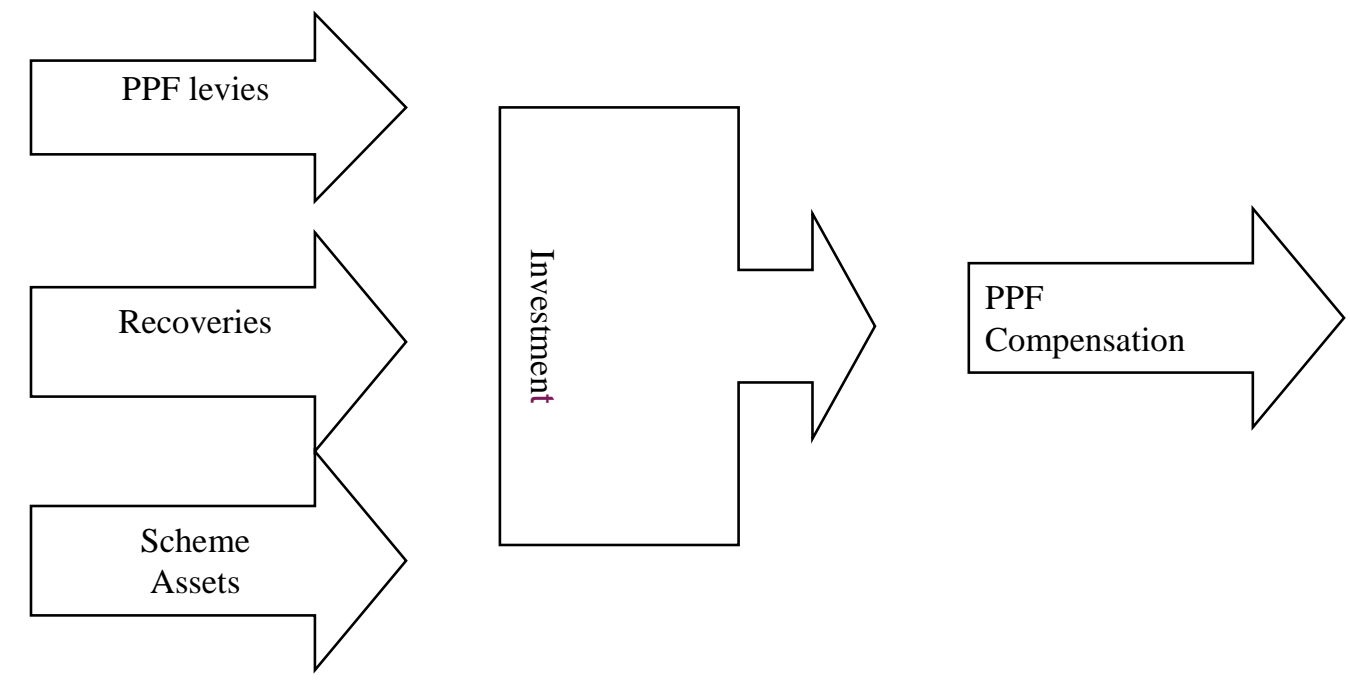

Figure 2. The PPF financial operating model. Source: Author's elaboration. 


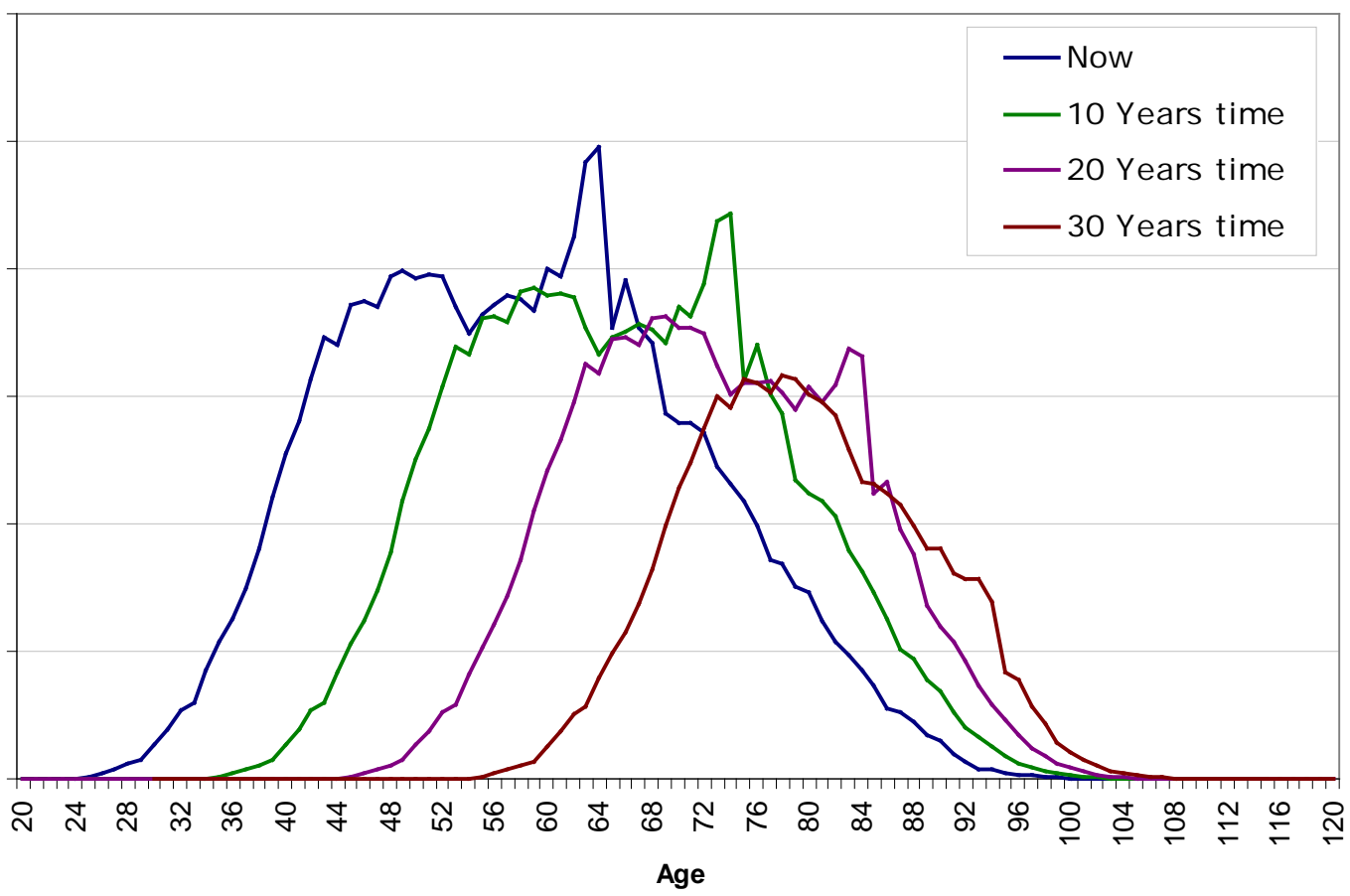

Figure 3. Projected development of the age profile of PPF membership. Source: Author's elaboration.

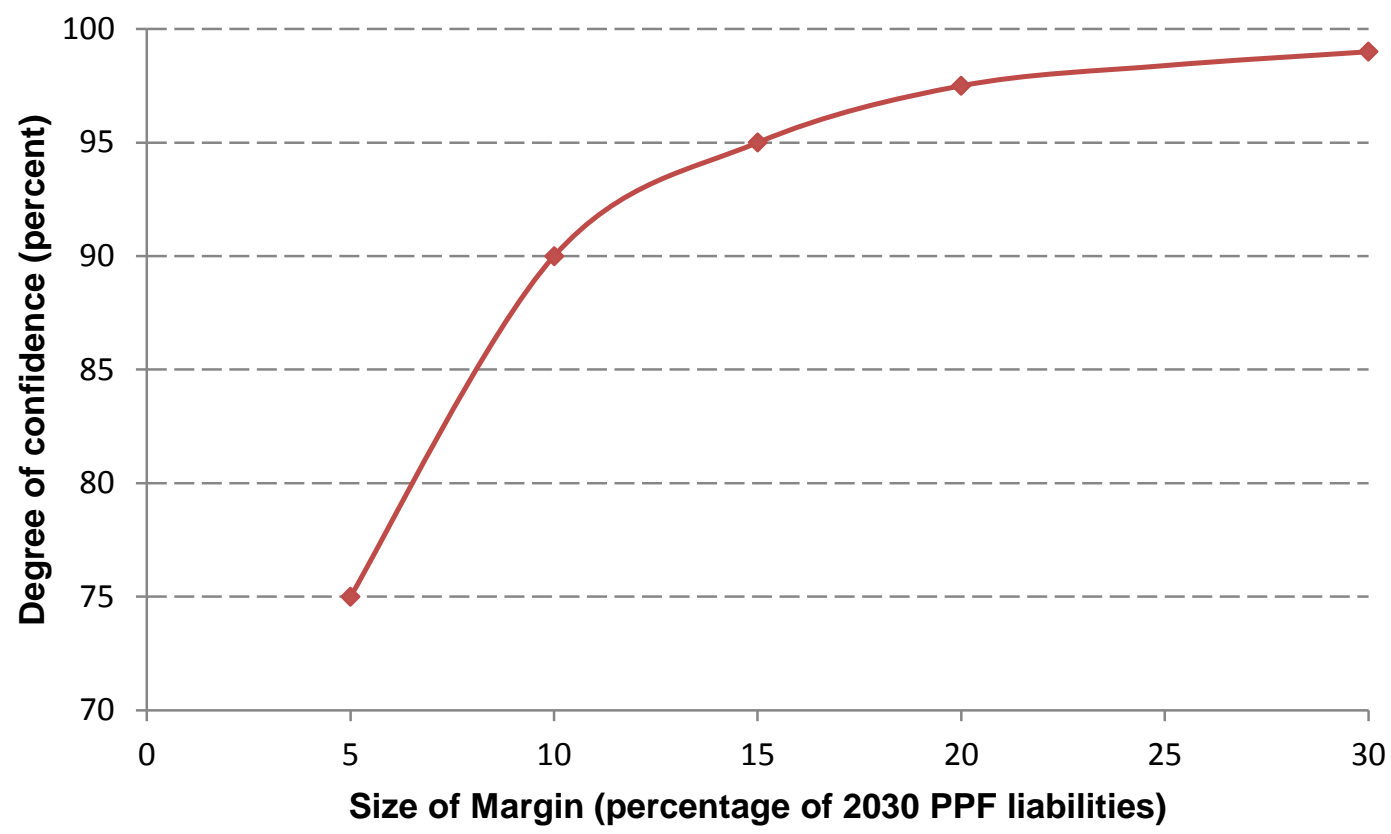

Figure 4. Funding margins for combined longevity and claims risk. Source: Author's elaboration. 


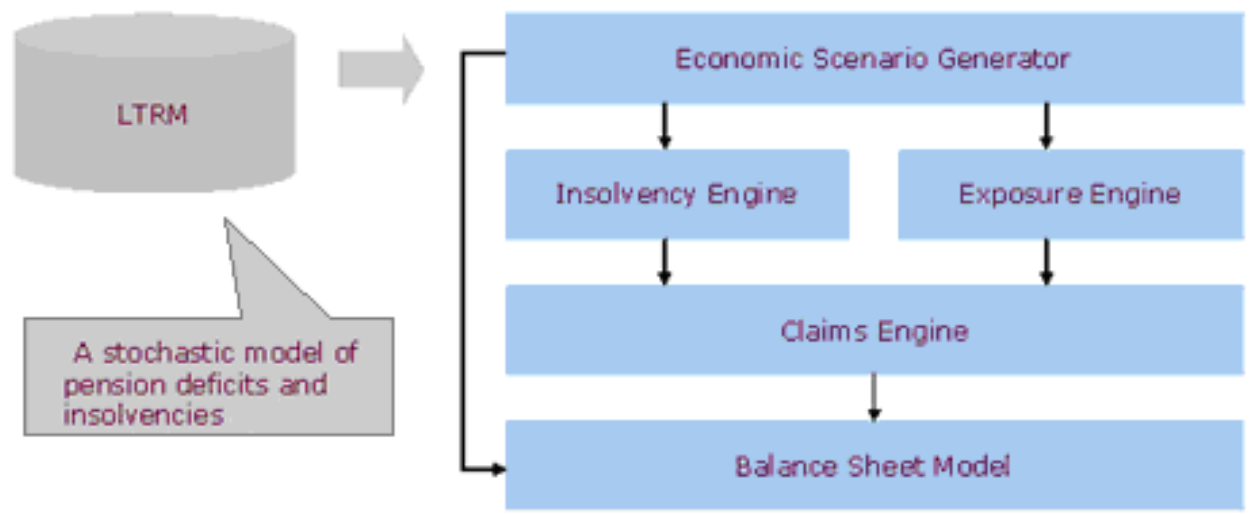

Figure 5. The internal model. Note: A third party economic scenario generator feeds two sub-modules that create consistent insolvency and exposure experiences respectively, combining to form distributions of PPF claims experience and balance sheet. Source: Author's elaboration.

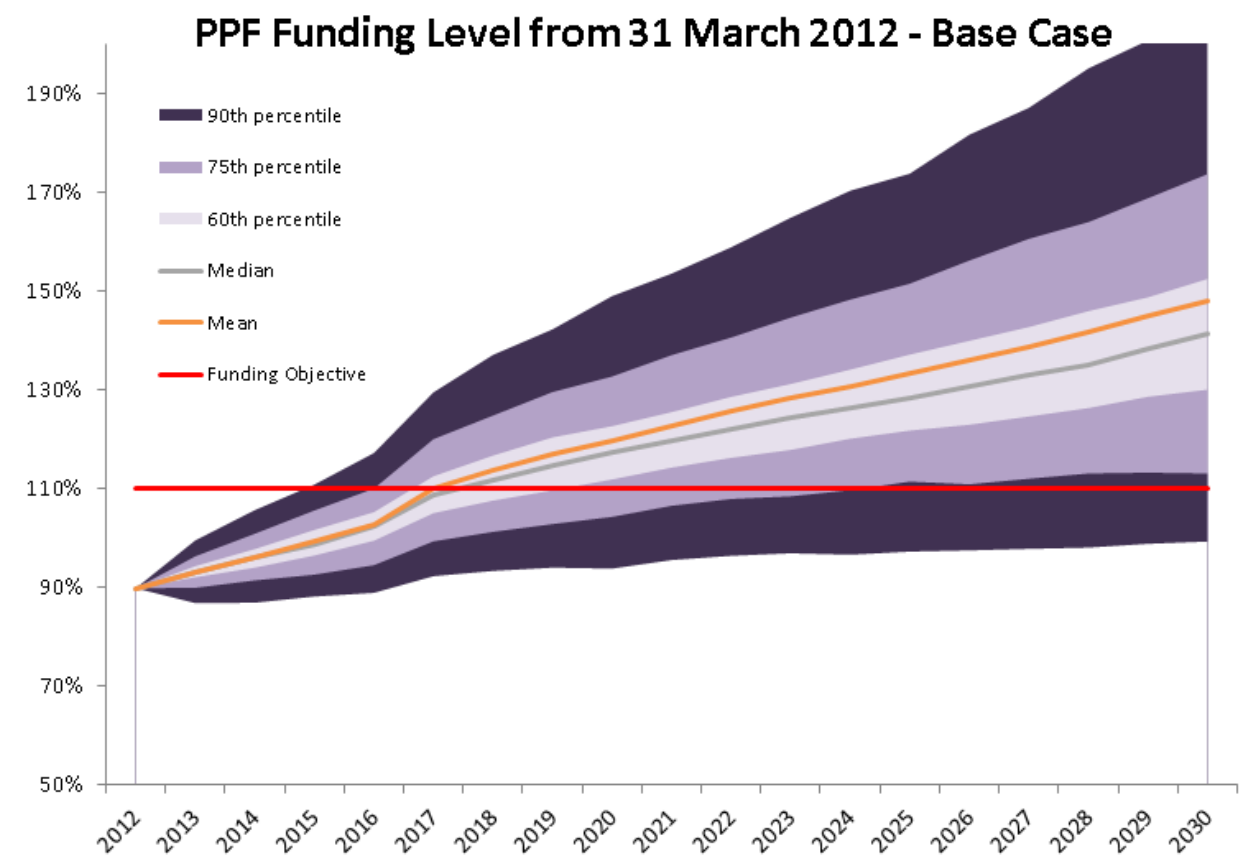

Figure 6. Distribution of balance sheet outcomes from the PPF's 31 March 2012 base case.

Source: PPF (2006-2013); PPF and The Pensions Regulator (2006-2013). 
Figure 7. PPF levy formula 2012/2013.

\section{Risk based levy $(\mathrm{RBL})=$ Underfunding (U) X Insolvency Risk (IR) X Levy Scaling Factor (LSF)}

Where

$U$ is the value of the scheme liabilities less the value of its assets and less any deficit reduction contribution made since the last valuation date. If $U$ is negative and the scheme is in surplus then the RBL is zero.

For the purposes of the above the assets and liabilities are stressed according to an adverse scenario to reflect investment risk.

$U$ may be further reduced if a contingent asset such as a bank or parental guarantee has been approved.

$R B L$ is capped at $0.75 \%$ of unstressed liabilities.

IR is a rate ranging from 0.0018 for the strongest sponsors up to 0.04 for the weakest. There are 10 categories in total.

$L S F=0.89$ for $2012 / 2013$

Scheme Based Levy (SBL) = Liabilities (L) X Scheme Based Multiplier (SBM)

Where:

$S B M=0.000085$

Source: PPF (2006-2013); PPF and The Pensions Regulator (2006-2013). 
Table 1 PPF Assets, Liabilities, Claims, and Levy Experience

\section{PPF Balance Sheet Development}

\begin{tabular}{|c|c|c|c|c|c|c|c|c|}
\hline Financial Year & $05 / 06$ & 06/07 & $07 / 08$ & 08/09 & $09 / 10$ & $10 / 11$ & $11 / 12$ & $12 / 13$ \\
\hline Assets (£m) & 2,086 & 4,409 & 5,554 & 9,330 & 12,257 & 14,043 & 16,513 & 18,898 \\
\hline Liabilities (£m) & 2,429 & 5,018 & 6,071 & 10,560 & 11,863 & 13,366 & 15,444 & 17,906 \\
\hline $\begin{array}{r}\text { Funding } \\
\text { Ratio }\end{array}$ & $86 \%$ & $88 \%$ & $91 \%$ & $88 \%$ & $103 \%$ & $105 \%$ & $107 \%$ & $106 \%$ \\
\hline $\begin{array}{l}\text { Claims in Year } \\
(£ \mathrm{~m})\end{array}$ & 485 & 442 & 318 & 721 & 285 & 373 & 375 & 1,000 \\
\hline $\begin{array}{l}\text { Levy collection } \\
\text { (£m) }\end{array}$ & 137 & 271 & 585 & 651 & 592 & 663 & 596 & 630 \\
\hline
\end{tabular}

Source: PPF (2006-2013); PPF and The Pensions Regulator (2006-2013). 
Table 2 Sensitivity of Downside Risk and Probability of Success

\section{Scenario}

Base case as at $31^{\text {st }}$ March 2012

Levy reduced by $10 \%$

25 bps reduction in asset returns (excluding cash and government bonds)

Initial PPF funding reduced by 10 percentage points

Length of recovery plans increased by three years

Reduced funding owing to a $10 \%$ reduction in scheme technical provisions.
Probability of success (\%)

84

10

82

11

82

11

79

12

83

11

79

15

Source: PPF (2006-2013); PPF and The Pensions Regulator (2006-2013). 